\title{
NÃO MATE AS BIXAS, DEIXE-AS VIVER! PENSANDO O DIREITO À VIDA A PARTIR DOS APONTAMENTOS DE EMMANUELLEVINAS
}

\author{
Thiago Henrique Almeida de Carvalho ${ }^{1}$ \\ David Ferreira de Araújo ${ }^{2}$
}

\begin{abstract}
RESUMO: O presente trabalho busca refletir, a partir dos apontamentos teóricos de Emmanuel Levinas, o direito à vida, uma vez que alguns "cidadãos de bem" se acham no direito de escolher quem pode e deve viver. Assim, torna-se necessário questionar as constantes mortes e perseguições à comunidade LGBT+, tendo em vista a nossa atual situação política-ideológica heteronormativa que, através do atual presidente da república Jair Messias Bolsonaro e de suas pautas governamentais, faz por disseminar discursos de ódio contra tais minorias. Logo, torna-se fundamental discutir, além do atual cenário compulsório que legitima a heterossexualidade como forma "sadia" de viver a sexualidade, sobre a falta de cuidado com outro e as diferentes forma de viver. Assim, cremos existir somente uma forma de viver nossa sexualidade, fazendo das outras uma "aberração" e "pecado". Tais idealizações refletem diretamente em formas de violência tanto simbólica quanto física, acarretando em mortes de pessoas LGBT's. Desta forma, a partir dos apontamentos teóricos de Levinas (2010), refletiremos sobre o não matarás. Não matem as bixas, deixem-as viver e sonhar. Desse modo, para dar sustentação a discussão tecida aqui, seguimos os preceitos da pesquisa bibliográfica, que é desenvolvida diante de material já elaborado, constituído de livros e artigos científicos.
\end{abstract}

Palavras-chave: Emmanuel Levinas; Direito à vida; Não matarás; Heteronormatividade; LGBT+.

\section{DON'T KILL THE QUEERS, LET THEM LIVE! THINKING ABOUT THE RIGHT TO LIFE BASED ON EMMANUEL LEVINAS' NOTES}

\begin{abstract}
This paper seeks to reflect, based on the theoretical notes of Emmanuel Levinas, on the right to life, since some "good citizens" think they have the right to choose who can and should live. Thus, it becomes necessary to question the constant deaths and persecutions of the LGBT+ community, considering our current heteronormative political-ideological situation that, through the current president of the republic Jair Messias Bolsonaro and his governmental guidelines, disseminates hate speech against such minorities. Therefore, it becomes fundamental to discuss, besides the current compulsory scenario that legitimizes heterosexuality as a "healthy" way to live sexuality, about the lack of care for the other and the different ways of living. So, we believe that there is only one way to live our sexuality, making others an "aberration" and a "sin".
\end{abstract}

\footnotetext{
${ }^{1}$ Licenciado em Ciências Sociais pela Universidade Federal de Pernambuco e Mestrando do Programa de Pós-Graduação em Antropologia pela mesma instituição de ensino. E-mail: carvalhothiago.1994@gmail.com

${ }^{2}$ Bacharel em Ciências Sociais pela Universidade Federal de Pernambuco e Mestrando do Programa de Pós-Graduação em Sociologia pela mesma instituição de ensino. E-mail: davidfaraujo1997@gmail.com
} 
Such idealizations reflect directly in forms of violence, both symbolic and physical, leading to the death of LGBT people. Thus, based on the theoretical notes of Levinas (2010), we will reflect on the thou shalt not kill. Don't kill the queers, let them live and dream. In this way, to support the discussion here, we follow the precepts of bibliographic research, which is developed using already prepared material, consisting of books and scientific articles.

Keywords: Emmanuel Levinas; Right to life; Thou shalt not kill; Heteronormativity; LGBT+.

\section{INTRODUÇÃO}

Todos são iguais perante a lei, sem distinção de qualquer natureza, garantindose aos brasileiros e aos estrangeiros residentes no País a inviolabilidade do direito à vida, à liberdade, à igualdade, à segurança e à propriedade. (Art. $5^{\circ}$ da Constituição Federal Brasileira - dos direitos e garantias fundamentais-, BRASIL, 1988.)

Como citado acima, o direito à vida é uma garantia fundamental a todos e a todas, ou seja, independente de religião, raça, gênero e sexualidade, todos são iguais perante a lei e devem ser respeitados. Todavia, o que deveria ser uma garantia a todos e a todas, restringe-se, aos então homens e mulheres materializados sobre a erguesse biologizante dos órgãos, ditados conforme uma heterossexualidade compulsória, ou seja, a coerência entre sexo-gênero-sexualidade (BUTLER, 2017). Dado isso, todos aqueles/aquelas que desviam dessa lógica são condenados aos olhos da sociedade. Assim, tem-se a justificativa de odiar, violentar e matar, lésbicas, gays, bissexuais, transexuais e travestis, uma vez que os grupos dominantes impõem suas forças seja social, econômica ou fisicamente, ditando regras e sentidos, e fazendo com que estejamos assujeitados aos esquemas e valores impostos pela totalidade (SAYÃO, 2017). Assim, aquelas e aqueles que possuem o direito de viver são os indivíduos, que segundo a lógica da heterossexualidade compulsória, possui uma coerência entre sexo/gênero/desejo (BUTLER, 2017). Enquanto as outras sexualidades são julgadas como aberrações, divergindo não apenas da única forma de viver uma sexualidade "sadia", mas desafiando um jogo politico que cobrará desses indivíduos marginalizados suas vidas. As mortes que assolam a comunidade $\mathrm{LGBT}+{ }^{3}$ justificam-se pelo fato dos viventes hegemônicos, isto é,

\footnotetext{
3 É a sigla para definir Lésbicas, Gays, Bissexuais, Travestis, Transexuais, Transgêneros, Queer (atua com a ideia que abrange as pessoas de ambos os gêneros que possuem uma variedade de orientações, 
homens e mulheres que possuem, de acordo com os pressupostos ocidentais, os órgãos biológicos vaginas e pênis, não acessarem, através de suas consciências, o direito à vida e o não matarás, independente de credo religioso, de raça, gênero e sexualidade.

Tendo em vista isso, este trabalho se justifica por refletir sobre a responsabilidade com o outro, o cuidar e o momento ético (Levinas, 2010). Antes de mais nada, é sobre o "não matarás" seja quem for. Além do mais, ele se constitui também pelas reflexões sobre as mortes que assolam constantemente o universo LGBT+, uma vez que essas pessoas, aos olhos do sistema imperativo heterossexual, são "degeneradas" e, constantemente, delas são retiradas seus direitos de viver. Assim, refletiremos sobre como essa moral, caracterizada a partir de um sistema de regras de uma sociedade, determina a conduta do que seja permito aceitar ou não, como também como essas regras são sancionadas e impostas aos indivíduos como incontestáveis (Durkheim, 1994 apud Weiss, 2007). Ademais, contestaremos o sistema político-ideológico da heterossexualidade compulsória, pensado a partir do fundamento individualista: eu enxergo meu próprio umbigo, nego as diversas naturezas e outros modos de viver e, consequentemente, cristalizo a violência. Portanto, o objetivo deste artigo é refletir, a partir dos apontamentos teóricos do filósofo Emmanuel Levinas, sobre o direito à vida dos LGBT's, tendo em vista a política massacrante em torno dessa população. Assim, cabe refletir sobre o "não matarás" como uma exigência da própria condição humana, pois, antes de tudo, devemos respeitar a humanidade, suas diversidades, fazendo por imperar a generosidade (Sayão, 2017). Dessa forma, para dar sustentação a discussão tecida aqui, seguimos os preceitos da pesquisa bibliográfica, que, segundo Gil (2008), é desenvolvida diante de material já elaborado, constituído de livros e artigos científicos.

\section{PENSANDO A REALIDADE A PARTIR DA COMUNIDADE LGBT+}

Como filósofos e pensadores, temos a responsabilidade de nos encharcar com as demandas próprias do nosso tempo, com os desafios maiores dos nossos

\footnotetext{
preferências e hábitos sexuais, ou seja, um termo neutro que possa ser utilizado por todos os adeptos desse movimento), Intersexo (pessoas em que a sua característica física não é expressa por características sexuais exclusivamente masculinas ou femininas) e assexual (pessoa que não possui atração sexual nem por homens e nem por mulheres ou que não possue orientação sexual definida). FONTE: http://prceu.usp.br/uspdiversidade/lgbtqia/o-que-e-lgbtqia/ acesso: dia 26/12/2019, às 15:30.
} 
dias e com os grandes dilemas que nos cercam, isso, mesmo que de forma não direta, mesmo que sem se envolver com as demandas práticas do mundo. (SAYÃO, 2011, p.99).

O referente tópico se constituirá a partir das reflexões de responsabilidade diante das nossas demandas do tempo atual, tendo em vista que enquanto filósofos, sociólogos e/ou antropólogos, temos o dever de levar em consideração os dilemas e as demandas práticas do mundo atual. Assim, constituímos e/ou construímos, por exemplo, sistemas, teorias, classificações etc em cima de um tempo que é passado, deixando o agora escapar, não problematizando as experiências dos nossos dias.

Dessa forma, a citação desenhada acima, corresponde ao que Levinas (2010), em seu livro Entre nós: ensaios sobre a alteridade, se propõe, tratando-se da ética da alteridade segundo a lógica da responsabilidade com o outro e com nossa demanda atual. Assim, essa ética tem fundamento na relação do mesmo com o outro, sendo levado em consideração a responsabilidade de orientar homens e mulheres ao "caminho da humanização", do respeitar o outro e do cuidar independente de sua particularidade. Dessa forma, a principal inquietação do autor, é eliminar a indiferença ética, uma vez que, ao estarmos posicionados sobre o mundo, estamos fortemente sofrendo influências desse. Logo, é na desestabilização desse mundo caótico e egoísta que veremos surgir a possibilidade de construção de uma responsabilidade que se manifestará a partir da preocupação e do engajamento do outro (LEVINAS, 2010).

Destarte, é através do humanismo que apresentaremos ao outro o momento do diferente, fazendo com que seja norteado aos indivíduos um mundo totalmente diferente do que estamos acostumados a viver, ou seja, onde a paz e o amor prevaleça. Será assim que conseguiremos sanar, acreditamos nós, bem como Levinas (2010), perspectivas egoístas e vontades individuais, priorizadas a todo custo pelo capitalismo como modo de viver e ser feliz, que faz gerir a infelicidade, a indiferença e a violência, pois, ao cuidar somente da nossa individualidade, esquecemos o outro, priorizamos nossas vontades, vemos somente as coisas que nos convém, respeitamos apenas nossos ideais e aquilo que enxergamos e fazemos imperar o caminho da injustiça, da solidão e do desprezo por aqueles/aquelas que divergem de nós. Por isso, temos que assumir a todo instante, a preocupação com as demandas práticas do mundo real (SAYÃO, 2011), temos o dever 
de questionar e debater nossa realidade e nossos problemas, visto que ela se apresenta fielmente diante de nós.

Por mais, como cientistas, devemos prestar atenção ao nosso tempo, pois nossa realidade deve ser percebida e questionada agora. Dessa maneira, é importante nos atentarmos a questão do tempo, não deixando as coisas escaparem de sua crítica e reflexão antes o processo de aceleração do tempo, pois o tempo passa rápido e as coisas mudam (BERGSON, 2006). Assim, não podemos parar no tempo, ele urge, necessita de criticas, de experiências vividas, bem como de maneiras de viver o mundo agora. Para tanto, necessitamos indagar nossas produções científicas, disciplinas e sistemas, ou melhor, o nosso agora, para que não seja tarde demais, uma vez que nossa realidade se constrói do agora e não somente do passado (BERGSON, 2006).

\begin{abstract}
O que mais faltou à filosofia foi a precisão. Os sistemas filosóficos não são talhados na medida da realidade em que vivemos. São largos demais para ela. Examinem um dentre eles, convenientemente escolhido: verão que se aplicaria com igual propriedade a um mundo no qual não houvesse plantas nem animais, mas apenas homens; no qual os homens deixariam de beber e de comer; no qual não dormiriam, não sonhariam nem divagariam; no qual nasceriam decrépitos para terminar bebês; no qual a energia subiria a encosta da degradação; no qual tudo iria a contrapelo e estaria ás avessas. É que um verdadeiro sistema é um conjunto de concepções tão abstratas e, por conseguinte, tão vastas, que nele caberia todo o possível, e mesmo o impossível, ao lado do real. (BERGSON, 2006, p.3).
\end{abstract}

Consequentemente, Bergson, em O pensamento e o movente (2006), questiona os sistemas filosóficos e quanto esses são construídos e delineados mediante uma determinada parada esporádica de tempo. Logo, criam-se sistemas abstratos que não conseguem acompanhar nossa realidade. Os indivíduos, por exemplo, deslocam-se constantemente e se movem num tempo que tem duração agora. Entretanto, os esquemas e estudos filosóficos se paralisaram no tempo, fazendo por acompanhar sujeitos que se moveram em um tempo já passado. Todavia, trata-se de reconhecer que nossas realidades não são estaticamente paralisadas no tempo, ela nos acompanham e são frutos do real e do concreto (BERGSON, 2006). Então, que acompanhemos o presente, aquele que decorre do real e do vivido, sobre qual se refere as percepções do presente e onde os sujeitos estão ocupados, necessariamente de uma duração. Para mais, o tempo torna-se um ponto de reflexão muito importante para Bergson (2016), sendo necessário evidenciar 
que este tempo é decorrente de uma duração, fazendo fomentar a percepção como um movimento do pensamento (BERSGON, 2006). Por via, é através desse tempo presente real e concreto, como já suscitado, que corresponde a nossa existência, onde nossas sensações criam, mediante conexões com o agora, ou seja, com o tempo e o espaço, a imagem direta do real (BERGSON, 2006). Sobre isso, passemos agora a questionar os conceitos utilizados, seja na filosofia, na antropologia, sociologia etc, enquanto frutos de acontecimentos, isto é, de uma duração que surge diante do sujeito por meio de sua experiência, do viver o hoje e dos problemas atuais.

Deste modo, o presente trabalho retrata nossa concreta realidade, esta altamente excludente e violenta, a qual não apenas se utiliza dos meios violentos para destruir o outro, tendo em vista seu modo de vida e/ou sexualidade destoar de um padrão hegemônico heterossexual. Cabe entretanto, antes de mais nada, pontuar que o "acabar com o outro que diverge de mim" não se conflui apenas à comunidade LGBT+, mas a todos: aos negros, aos índios, às mulheres, aos próprios heterossexuais etc. ${ }^{4}$ Assim, o "não matarás" não se torna exclusivo ao movimento LGBT+, este se direciona a todos e todas. Todavia, este artigo se possibilita a reconhecer as mortes que assolam os LGBT's, tornando-se essencial realizar um recorte destinado a esta população, reconhecendo o atual momento político-ideológico do Brasil, onde esta comunidade se torna a mais afetada física e psicologicamente pela violência. Logo, reconhecemos que os vieses egoístas e da indiferença ética levam, posteriormente, à violência tanto física quanto simbólica, bem como à morte, sendo estas não fruto do nosso agora, mas de um contexto histórico que sempre encarregou de perseguir, difamar e matar LGBT's. Essa relação histórica se delineia, de uma forma ou de outra, através do que Foucault (2014) chama de sociedade disciplinadora, na qual se procura interferir na vida daquele que diverge dos padrões ideais de sociedade. Trata-se, então, "de uma nova forma de poder que decide e ritualiza a morte para uma nova forma de poder que planeja tecnicamente a vida em termos de população, saúde e interesse nacional” (PRECIADO, 2018, p. 75).

Biopoder é o termo com que se refere a essa nova forma de poder produtivo difuso e em expansão. Ultrapassando o domínio jurídico e da esfera punitiva, o poder torna-se uma força de somatopoder que penetra e constitui o corpo do

4http://agenciabrasil.ebc.com.br/geral/noticia/2019-06/ipea-homicidios-de-mulheres-cresceram-acima-damedia-nacional acessado dia 26/12/2019 ás 19:05 


\begin{abstract}
indivíduo moderno. Este poder já não se comporta como uma lei coercitiva, um mandato negativo: é mais versátil e acolhedor, adquirindo a forma de "uma arte de governar a vida", uma tecnologia política geral transformadora em arquiteturas disciplinadoras (prisões, quartéis, escolas, hospitais etc), textos científicos, tabelas estatísticas, cálculos demográficos, manuais, recomendações de uso, calendários de regulação reprodutiva e projetos de saúde públicas. Antes de nada, Foucault sublinha a centralidade do sexo e da sexualidade nessa moderna arte de governar a vida. (PRECIADO, 2018, p. 75/76).
\end{abstract}

Sendo assim, diretamente e institucionalmente ou não, através dos aparatos médicos e tecnológicos, dos discursos e valores sociais e morais, bem como culturais, buscou-se enquadrar e desarticular as sexualidades desviantes, tendo em vista seu poder de desestabilizar as normas vigentes e seus aparatos ideológicos que pregam a estabilização de valores heterossexuais. O Brasil, por exemplo, como informa Trevisan (2018), utilizou-se de guias médicos para classificar a homossexualidade e as outras sexualidades divergentes como doença. Foi através de guias homeopatas, do século XX, que se tornaram mais evidentes os embasamentos de desordens sexuais. Entretanto, foi em meados do século XIX, que abundaram as abordagens científicas sobre as condenações das sexualidades "abjetas", cuja pretensão era classificar indivíduos como loucos e mentalmente alienados (TREVISAN, 2018). Como se pode perceber, setores como a medicina e posteriormente a jurisprudência brasileira começaram a disseminar que tais sexualidades, "as abjetas ${ }^{5} \mathrm{e}$ as pervertidas", bem como os atos sexuais que se diferenciavam da prática heteronormativa, seriam "errôneas", "contra a natureza", seriam elas consideradas uma "anomalia". Por isso, como afirma Sibilia (2015), para fazer circundar tais concepções como verdades inabaláveis, as relações de poder operam como vetores produtivos, exercendo, junto às forças sociais, transformações. Isto é, o poder atua ao lado do saber e fica responsável, como se permite compreender, através das discussões teóricas de Foucault, sobre as mais influentes táticas de controle sobre os sujeitos. Dito isso, sendo tais sexualidades "desviantes", contra uma suposta "natureza humana", nada mais justificável, diante do sistema político heteronormativo, de disseminar um discurso de ódio violentador, levando ao outro à privação do seu direito de viver.

5 Cabe salientar que o termo "abjeção e/ou desviante" "se refere ao espaço que a coletividade costuma relegar aqueles e aquelas que consideram uma ameaça ao seu bom funcionamento, à ordem social e política" (MISKOLCI, 2017, p. 24). 
Logo, não data de hoje as concepções brutais de classificar as sexualidades, que divergem dos padrões heterossexuais, como desviantes, como também as diversas formas de violência, seja física ou simbólica em torno da comunidade LGBT+. Apesar dos mais inúmeros avanços, tais como o reconhecimento da luta LGBT, retirada da homossexualidade da lista de doença mental, o reconhecimento da transexualidade e a sua retirada da OMS (Organização Mundial de Saúde) como portadoras de transtornos de identidade de gênero, a aprovação pelo Supremo Tribunal Federal, da criminalização da LGBTfobia $^{6}$ (este último em 13 de Junho de 2019, referente ao Brasil), dentre outras coisas, esses pequenos avanços nos diz muito pouco diante das alarmantes mortes de gays, lésbicas, bissexuais, transexuais, travestis etc, uma vez que, com o crescimento da nova direita política e de suas políticas moralizantes a partir de 2013, emerge, no país, um cenário conservador que atinge principalmente os cidadãos LGBT's. Assim, o reflexo desse cenário caótico começa a ser desenhado na câmara dos deputados, através do então pastor-deputado e presidente da Comissão de Direitos Humanos Marco Feliciano, por meio de suas declarações racistas e LGBTfóbicas, fazendo por reascender forças políticas conservadoras.

\begin{abstract}
Com a eclosão das questões de identidade de gênero e elaborações teóricas correlatas, no início do século XXI, a agenda LGBT provocou renovado interesse dos conservadores e acirramento do debate. A eleição de Donald Trump à presidência dos Estados Unidos, em 2016, foi determinante na intrincada articulação de uma nova direita política, muitas vezes sucedendo governos mais progressistas em várias partes do mundo, inclusive no Brasil. Nesse bloco movido por revanchismo, paranoia política e fundamentalismo religioso, incorporam-se diferentes tendências conservadoras e autoritárias, de cunho ora nacionalista-populista, ora teocrático, ora militarista ou francamente fascista. Abusando do território caótico da internet, o clima de ódio trouxe à cena o conceito de pós- verdade, baseado nas fake news e na arte de manipular multidões. (TREVISAN, 2018. p. 439).
\end{abstract}

À vista disso, em meio a essas ondas conservadoras, instaurou-se fortes apelos morais, como "Deus fez o homem para a mulher e vice-versa". Portanto, seja a filosofia, antropologia ou demais disciplinas, elas devem se constituir diante desses fatos do agora e do que se passa em nossa sociedade, ou seja, dessa e de outras realidades do nosso cotidiano. Para mais, a reflexão desenhada acima, fez por emergir nosso dever enquanto

6https://www.cartacapital.com.br/justica/por-8-a-3-stf-aprova-a-criminalizacao-da-lgbtfobia/ Acessado no dia 02/02/2020, ás 20:46. 
pesquisadores e cientistas de levar em consideração a responsabilidade com o nosso tempo, de questionar os paradigmas e conceitos que jã não dão mais conta da nossa realidade, pois diante de novas indagações, necessita-se de atuais formas de pensar e teorizar. Sendo assim, devemos sempre ter consciência desse papel, para que possamos fazer uma ciência da realidade presente. Logo, fazendo alusão a essa realidade presente, o próximo tópico se debruçará ainda mais diante disso, elucidando dados sobre as mortes de pessoas LGBT's.

\section{OS DADOS NÃO METEM, AS BIXAS ${ }^{7}$ ESTÃO MORRENDO}

Enquanto que no tópico anterior foi apresentado o questionamento sobre a filosofia enquanto ciência, que não consegue dar conta da realidade, e o nosso dever enquanto pesquisadores, que devemos nos atentar em dar conta da realidade vivida agora, no que se refere a este tópico, apresentaremos, diante de dados de matérias jornalisticas, as avassaladoras mortes de pessoas que são da comunidade LGBT+, a fim de, então, elucidar a política heteronormativa de perseguição e morte às sexualidades "abjetas", tendo em vista seu teor desestabilizador.

Sendo assim, de acordo com a matéria disponibilizada pelo portal de notícias brasileira $(\mathrm{G} 1)^{8}$, a cada 23 horas morre uma pessoa LGBT+ no Brasil. Ainda de acordo com a matéria, desde o início de Janeiro ao dia 15 de Maio de 2019, segundo o Grupo Gay da Bahia (GGB), foram registradas 141 mortes, um número muito expressivo e significante que reflete nossa atual situação política de intolerância àqueles que divergem do sistema compulsório heterossexual. Para mais, este imperativo compulsório impregna os sistemas políticos e os valores da nossa sociedade, fazendo das nossas condutas um constante ato disciplinador, ou seja, estamos constantemente, através dos conjuntos do biopoder, sendo controlados e manipulados. Como afirma Foucault (2014), instauram-se comunicações que são úteis tanto para controlar o indivíduo quanto para interromper

\footnotetext{
7 Segundo Vidarte (2019), bixa é um termo que engloba as siglas LGBT+. A palavra bixa, que na década de 1970/1980, era voltada aos então homossexuais, agora tem uma nova ressignificação: somo bixas, somos orgulhosas, somos aquilo que diverge do sistema opressor heterossexista, somos liberdade, somos brilho, somos bixas LGBT+'s. Além do mais, este termo torna-se importante, porque dado seu sentido pejorativo, ele é redefinido, motivo de orgulho e pertencimento,

8https://g1.globo.com/sp/sao-paulo/noticia/2019/05/17/brasil-registra-uma-morte-por-homofobia-a-cada23-horas-aponta-entidade-lgbt.ghtml. Acessado dia 03/01/2020 ás 12:30. 
situações perigosas, tratam-se de poderes que vigiam e controlam nossas identidades, comportamentos, corpos e sexualidades.

Dessa forma, uma vez escapando dessa rede de poder que interrompe situações perigosas, você esta a mercê das mais altas retaliações: exclusão de um estrutura que possibilita uma morte social - marginalidade, precariedade, acesso restrito a serviços públicos, exclusão da escola, da família e principalmente do mercado de trabalho. Devese reconhecer que tal exclusão se dar em maior peso para as siglas TT's (Travestis e Transexuais). Contudo, reconhecemos que a marginalidade acompanha toda a sigla LGBT+. Essas pessoas estão ao próprio alento, são expostas, são violentadas física e psicologicamente, são, como afirma o imperativo heterossexual, transgressoras, merecem um "corretivo", "uma surra/apanhar", "castigos", "desprezo" e consequentemente "a morte", não a simbólica, tida como um tipo de exclusão social, mas a morte reconhecida por eliminar o outro pela divergência de sua particularidade ${ }^{9}$.

Apesar da palavra ser impactante, a morte ronda a comunidade LGBT+ por estes não terem suas particularidades respeitadas, uma vez que a heteronormatividade cobra que sejamos indivíduos que desempenhe papéis masculinos e femininos dado a materialidade do sexo. Por isso, torna-se extremamente inaceitável desafiar o que a compulsoriedade heterossexual chama de natural: sexo, gênero e sexualidade (BUTLER, 2017). Assim, diante dessa lógica, casos de mortes aos LGBT's são veemente cometidos. A morte de Dandara, por exemplo, reflete tal tipo de atitude que se tem pelo outro que é diferente. Após agressões com chutes e golpes de pau, a travesti Dandara dos Santos foi assassinada a tiros, segundo o secretário da Segurança Pública e Defesa Social do Ceará, delegado André Costa. Os dois suspeitos de atirar em Dandara foram presos, conforme o secretário. Também foram apreendidos três adolescentes que aparecem no vídeo agredindo a vítima e um sexto suspeito que está foragido (PORTAL G1, 2017) ${ }^{10}$.

\footnotetext{
9 Por mais que a questão da identidade seja tangencialmente tratada neste trabalho, não temos como pretensão a abordar a partir do pensamento de Levinas, tendo em vista que para o autor a identidade se refere à totalidade, trazendo consigo determinadas violências ao outro. Dito isso, abordamos essa questão mais próxima do pensamento Butler (2017), onde a identidade não é uma imposição, porém sim uma escolha, na qual o queer, que é o outro, o não normativo, deve ser respeito.

10 Retirado da reportagem do G1: http://g1.globo.com/ceara/noticia/2017/03/apos-agressao-dandara-foimorta-com-tiro-diz-secretario-andre-costa.html. Acessado dia 04//01/2020, ás 16:30
} 
Outro caso de grande repercussão foi o da travesti afro-indígena Maria ${ }^{11}$, ela foi espancada por oito homens após apenas pedir um isqueiro emprestado para um vendedor ambulante em uma barraca localizada em uma praça movimentada de Niterói, cidade vizinha a do Rio de Janeiro. Ela estava com um grupo de amigos LGBT's, quando o comerciante começou a discutir de forma agressiva com ela. Durante a briga, outros sete homens que estavam no local se juntaram a ele para agredi-la com socos e pontapés, enquanto gritavam xingamentos transfóbicos. Para finalizar, o chocante caso da travesti Quelly $^{12}$ da Silva, assassinada no inicio de 2019, em Campinas/São Paulo, em um bar da região de Campo Belo. Ela teve o coração arrancado e, até o caso ganhar repercussão nacional, era tratado como "morte aleatória" nas investigações da polícia.

Mas por que tantos casos de violências e mortes a LGBT's? Pelo medo de reconhecer o outro como diferente do nosso ideal heteronormativo, pela forma que tal sistema político nos condiciona a enxergamos apenas o masculino e feminino heterossexual como "natureza humana" e como "aceitável", por conta do teor desestabilizador que tais sexualidades desviantes carregam, por causa da particularidade político-ideológica que atinge o outro e faz da sua visão uma forma universal de ser. Por isso, a sociedade, especificamente suas instituições, tem a preocupação de adestrar as identidades, as sexualidades e os corpos dos sujeitos com as normatividades a partir de normas criadas historicamente, tendo por intencionalidade à preservação de uma pedagogia heterossexual, isto é, aquela que limita os indivíduos modernos à essência de representações masculinas e femininas coerentes, estimulando-os a uma corporeidade materializada no sexo (LOURO, 2016).

\footnotetext{
A heterossexualidade seria o elemento fundamental do estabelecimento de uma identidade universal coerente e contínua que institui que o sexo, o gênero e o prazer sexual se combinariam linearmente como sexo biológico, gênero culturalmente produzido e a manifestação do desejo em práticas sexuais que são expressões de ambos. "A heterossexualização do desejo requer e institui a produção de oposições discriminadas e assimétricas entre 'feminino' e 'masculino,' em que estes são compreendidos como atributos expressivos de 'macho' e 'fêmea"' (BUTLER, 2003, p. 38).
}

11 Retirado da reportagem: http://www.generonumero.media/transfobia-11-pessoas-trans-sao-agredidas-acada-dia-no-brasil-2/. Acessado dia 04/01/2020, ás 16:54

12 Retirado das reportagens: https://g1.globo.com/sp/campinas-regiao/noticia/2019/01/23/companheirode-travesti-que-teve-coracao-arrancado-diz-que-autor-nao-pode-viver-em-sociedade.ghtml https://www.extraclasse.org.br/movimento/2019/01/brasil-registra-mais-de-45-dos-assassinatos-detransexuais-no-mundo/ Acessado dia 04/01/2020, ás 17:03. 
Logo, nossas condutas são influenciadas pelos aparatos político-ideológicos que massivamente são sobrepostos no nosso cotidiano através do governo, mídia, escola, família etc - são vieses que fazem circundar ideais, por exemplo, de "masculinidade" e "feminilidade" com a devida sexualidade heterossexual. Tal jogo político excludente fundamenta discursos e práticas de ódios, garantindo à classe hegemônica o "direito" de discriminar e matar aqueles que destoam do padrão heterossexual e das formas de apresentar a coerência entre sexo/gênero/desejo sob a práxis política de controle dos corpos e das sexualidades “abjetas” (BUTLER, 2017).

Dessa forma, aplica-se sobre nós filtros do que se pode e não aceitar, do que se pode e não fazer. Posto isso, devemos ser aquilo que nossa sociedade permite, devemos reduzir nossas naturezas ao ser "homem" e "mulher", mantendo o status quo das coisas e dos seres. Precisamos, de acordo com tais estruturas compulsórias e excludentes, manter e reproduzir essa totalidade opressora e violenta que possibilita modelos de ser violentos (SAYÃO, 2017). Precisamos também, negar a multiplicidade e o "outro", tendo em vista a desestabilização que esse pode ocasionar: um "estado de selvageria", onde a natureza torna-se incontrolável e o medo, a violência e o caos possam comandar e interferir em nossos elementos básicos. Mas sobre qual "selvageria" estamos falando? Aquela que questiona os valores vigentes da nossa sociedade, ou seja, as normatizações envolvendo os padrões hegemônicos do que seja ser "homem" e "mulher" heterossexual e busca incluir esses sujeitos considerados "desviantes" em nossa sociedade ou aquele que visa excluir, marginalizar e jogar aos lobos (isto é, matar) os sujeitos que destoam do padrão hegemônico heterossexual de nossa sociedade, oficializando a diversidade como inimiga? Será o "estado de selvageria" aquilo que não pretende limitar os indivíduos e suas naturezas a meros objetos e coisas, respeitando seu direito de ir e vir, bem como o seu direito à vida, independente de raça, gênero e sexualidade, ou será o "estado de selvageria" aquilo que sempre buscou nomear e classificar os indivíduos a meros objetos e representações de masculinidade e feminilidade heterossexual, limitando, por assim, outros seres e outras naturezas?

Nossas afirmantes políticas heteronormativas, marginalizam as sexualidades divergentes, promovendo o exacerbado espelho e afirmações heterossexistas. Nosso 
maior exemplo é o presidente eleito Jair Messias Bolsonaro, em que constantemente seus discursos incitam violência aos LGBT's: "a minoria tem que se curvar para a maioria," "prefiro filho morto em acidente a um homossexual" e "o filho começa a ficar assim meio gayzinho, leva um couro, ele muda o comportamento dele"13. Como é perceptivo, vivemos em tempos sombrios, de discursos fundamentalistas bem articulados, de declarações de ódios, de violência e morte aos LGBT's e de raiva declarada ao diferente. Tudo isso vem à tona quando a totalidade é ameaçada, quando valores hegemônicos são questionados e a realidade instaurada é questionada (SAỸ̃O, 2017). Tendo isso em vista, assim como Emmanuel Levinas (2010), este trabalho se assenta na tentativa de salvaguardar a vida, respeitar a diversidade, incentivar a generosidade e a fraternidade como elementos primordiais de uma sociedade. Atenta-se também em refletir as estruturas da nossa sociedade, fazendo emergir, nas nossas instituições, uma consciência acolhedora que abdica do pleno e exclusivo uso dos poderes para reprimir o diferente, para trabalhar em função do não matarás seja quem for, do homossexual a travesti, do heterossexual a transexual (SAYÃO, 2017). Sendo assim, o próximo tópico se desdobrará, a partir dos ideais teóricos de Emmanuel Levinas, sobre o não matarás, o direito de viver e sobre a filosofia da justiça e do amor, baseado na relação da bondade e da preocupação com outro.

\title{
ANALISANDO OS DADOS À LUZ DO PENSAMENTO DE EMMANUEL LEVINAS
}

\begin{abstract}
Por essa razão, documentos, como a Declaração Universal dos Direitos Humanos, que buscam impedir todo e qualquer tipo de discriminação, seja ela social, intelectual, de força, de virtude e de talentos, bem como toda sorte de violência nascida de nossas peculiaridades étnicas, raciais, de gênero ou sexuais, carregam em si um declarado desejo de salvaguardar e zelar pelo nosso bem maior que é a vida. (SAYÃO, 2017, p. 46).
\end{abstract}

13https://www1.folha.uol.com.br/fsp/cotidian/ff2611201025.htm; https://www.terra.com.br/noticias/brasil/bolsonaroprefiro-filho-morto-em-acidente-a-um homossexual,cf89cc00a90ea310VgnCLD200000bbcceb0aRCRD.html; https://istoe.com.br/frases-de-bolsonaro-o-candidato-que-despreza-as-minorias/ Acessados no dia 04/01/2020, às 17:30. 
Conforme os tópicos anteriores, foi mostrado alguns dados sobre as mortes de pessoas LGBT's e o quanto a filosofia não consegue, através de seus conceitos abstratos do passado, dar conta da realidade em sua totalidade, o presente tópico analisará tais informações à luz do pensamento de Emmanuel Levinas (2010) do "não matarás" seja quem for, conduzindo-nos a uma ética da responsabilidade e preocupação com outrem. Sendo assim, como colocado na citação acima, a Declaração Universal dos Direitos Humanos atua buscando impedir qualquer que seja a discriminação e ato violento, contudo, a nova direita, através dos seus extremismos e de suas visões, põe em cheque constantemente a elaboração desse documento, com todas as passagens e razões de salvaguardar e zelar pela vida, independente de raça, credo religioso, gênero ou sexualidade. A nova direita acha então que tais declarações universais e seus extensos documentos operam em prol da defesa de "bandidos", ou seja, daqueles que "matam", "roubam" e "estupram", bem como de "desvirtuados", ou melhor, aqueles que não correspondem à concordância entre sexo/gênero/sexualidade, pondo em risco os valores da família tradicional brasileira. Todavia, cabe salientar

\footnotetext{
(...) que é um absurdo considerar que os Direitos Humanos defendam "a permissibilidade" ao crime. Essa afirmação é um estigma criado exatamente por quem deseja interditar e despotencializar a luta contra a barbárie e a exploração humana. E basta olhar para os grupos que lutam pelos Direitos Humanos em instâncias formalmente constituídas, para observar que em nenhum desses há a defesa de práticas ilícitas ou qualquer atividades que sejam contrárias à ética. E se os Direitos Humanos se colocam em defesa dos que cometeram atos infracionais, a fim de preservar a integridade e dignidade física e psíquica dos mesmos, é porque socialmente se chegou à conclusão que esse é um bem inalienável e que independente do que possamos fazer ou ser, certos limites devem ser respeitados. (SAYÃO, 2017, p. 40).
}

Mas então, como justificar, se é que se justifica, a morte de pessoas LGBT's conforme visto no tópico anterior? De acordo com Sandro Sayão (2017), o medo do outro diferente faz com que aqueles que se sentem ameaçados, tranquem-se em seu mundo fechado, acabando por associar que o outro é uma ameaça, um perigo para sociedade e um potencial inimigo. Assim, segundo tal viés, todo diferente acaba sendo mais cedo ou mais tarde, tudo aquilo que já é esperado, devendo ele então ser eliminado. Por mais, trata-se de um temor advindo do rosto de outrem, onde o matar esse outro nada mais é que um desejo de permanecer em si, com suas verdades inabaláveis, onde a ameaça e o 
risco são quase zero (SAYÃO, 2017). Se seguirmos estas ordens, seremos incapazes de lidar com a diversidade, mataremos não só LGBT's, mas aqueles que divergem de nós seja política, social e culturalmente. À vista disso, seremos sempre indiferentes ao outro, num mundo centrado no egoísmo e numa cultura violenta, incitando e estimulando a violência, fazendo dados e mais dados, trazendo morte e sofrimento. Como escapar disso? É através da generosidade e da hospitalidade que traremos o sentido do humanismo, onde o respeitar o próximo, o não matarás e o amarás o estrangeiro imperará.

\begin{abstract}
A lei do não matarás é parte central das escrituras antigas, que há muito reverberam como fonte de sabedoria a serem auscultadas pelas sociedades. Esse ponto, que para alguns poderia representar uma tendência à teologia e, desse modo, um demérito que lhe enfraqueceria a argumentação, indica na verdade o reconhecimento filosófico por Levinas, de um imperativo que é incoercível e não pode de modo algum ser equacionado. Caso contrário, a própria condição humana não se daria. Não matar, é uma exigência da própria condição humana. A humanidade depende do respeito a essa lei. Isso desde os momentos mais fundamentais, já que somos humanos porque nos erguemos na relação com os outros e no encontro com quem não matamos; caso contrário, se a morte e a violência fossem questões primaciais, nós simplesmente não seríamos o que somos. (SAYÃO, 2017, p. 44/45).
\end{abstract}

Por isso, mortes como a de Dandara dos Santos e Quelly da Silva, ambas travestis, e o espancamento da afro-indígena Maria são recorrentes em nossa sociedade, estamos socializados com a falta de generosidade, responsabilidade e hospitalidade com o outro, estamos, respectivamente, preocupados somente em si e no próprio bem-estar. Assim, mortes voltadas à comunidade LGBT+ se firmam diante da assimetria que se constrói política e ideologicamente: devemos desprezar o outro diferente, aquele que diverge dos ideais heteronormativos de gênero e sexualidade, pois "pouco me importa se o outro é diferente, pouco me interessa o que ele é em relação a mim” (LEVINAS, 2010). Diante desses dados, pouco se exercita o que Levinas (2010) nos deixou de reflexão, o outro como minha responsabilidade. Tendo esses dados como reflexão, o que poderíamos fazer enquanto pesquisadores e cientistas? Levar o momento ético em toda nossa trajetória, deixando sempre evidente que no mundo existe não somente um primeiro a chegar, há sempre um terceiro e que ele é meu outro. Cabe então, antes de mais nada, assumir responsabilidades com o outro e exercer a justiça diante de outrem. 


\begin{abstract}
Ali está a origem do teorético, ali nasce a preocupação com a justiça que é fundamento do teorético. Mas é sempre a partir do rosto, a partir da responsabilidade por outrem, que aparece a justiça, que comporta julgamento e comparação, comparação daquilo que em princípio, é incomparável, pois cada ser é único; todo outrem é único. Neste necessidade de se ocupar com a justiça aparece esta ideia de equidade, sobre a qual está fundada a ideia de objetividade. Há, em certo momento, necessidade de uma "pesagem", duma comparação, dum pensamento, e a filosofia seria, nesse sentido, a aparição da sabedoria a partir do âmago desta caridade inicial: ela seria - e não brinco com as palavras - a sabedoria desta caridade, sabedoria do amor. (LEVINAS, 2010, p. 144).
\end{abstract}

Nosso dever nada mais é do que fazer uma filosofia da justiça e do amor, atenuada ao nosso tempo, refletindo sobre o rosto de outrem na nossa sociedade, uma vez "que sempre há no rosto de outrem a morte e, assim, de certa maneira, incitação ao assassinato, tentação de ir até o fim, de negligenciar completamente a outrem” (LEVINAS, 2010, p. 131). Visto isso, não basta apenas refletir em cima dos dados e das mortes dos LGBT's, devemos pôr em prática, de fato, a responsabilidade pelo outrem, assumindo, por exemplo, o sofrimento do outro e o sofrer do outro (LEVINAS, 2010). Desta forma, ao dar prioridade ao outro, assumo uma responsabilidade com o mundo, na tentativa de torná-lo mais justo, dando oportunidade a todas e todos de se expressarem e viver. Em função disso, a humanidade necessita de responsabilidade e de acolhimento, necessita também da obrigação e respeito a outrem, precisamos despertar e ter consciência do nosso dever na sociedade e prezar pela caridade e justiça (LEVINAS, 2010).

Consequentemente, muitas das mortes aos LGBT's são compactuadas pela falta de responsabilidade com o outro, já que a todo custo, somos, pela sociedade do controle, estimulados a conter e/ou eliminar o diferente, tendo todo o anseio que este poderá causar. Tais mortes se tornam "banais", tendo em vista nossa atual situação política brasileira, estimuladora do viés heteronormativo, fazendo com que a onda da indiferença com o outro que é diferente de nós aumente mais. O caso, por exemplo, da travesti Quelly da Silva, que teve seu coração arrancado, apesar de atrair uma comoção, dar-nos mais dados para quantificar e refletirmos a realidade de grande parte dessa população, todavia, não existe justiça e amor, a bondade com essas pessoas tornam-se passageiras, quando na verdade, nunca existente. Ao invés de estimularmos os indivíduos a pensarem em seus direitos individuais, como, por exemplo, o acesso à propriedade privada, levemos em consideração, antes de tudo e em primeira instância, a bondade como direito que vem do 
homem, restringindo-se não somente a esse, mas às mulheres e aos LGBT's (LEVINAS, 2010).

\begin{abstract}
Des-in-ter-essamento da bondade: outrem em sua súplica, que é uma ordem, outrem como rosto, outrem que me "diz respeito" ("me regarde"), mesmo quando não me olha, outrem como próximo e sempre estanho - bondade como transcendência, e eu, aquele que é obrigado a responder, o insubstituível e, assim, o eleito e, desse modo, verdadeiramente único. Bondade para com o primeiro que vem, direito do homem. Direito do outro homem antes de mais nada. (Levinas, 2010, p. 266).
\end{abstract}

Sendo assim, refletindo tais dados a luz do pensamento de Emmanuel Levinas (2010), devíamos entender o outro como infinito, isto é, o outro é muito mais do que se pode imaginar, muito além da ideia que se pode formar, o outro agora é transcendente, infinito e não pode mais ser visto como objeto. Então, a partir disso, reconheceríamos o outro que difere de nós de várias formas e prezaríamos por sua vida, uma vez que ela é um direito inalienável a todos e todas. Trata-se de inverter esse jogo mortal que elimina os outros diferentes, saindo da função humano do em-si e voltar-se para-outro, o outro que precisa de mim, quanto nós podemos precisar do outro. Em suma, e dever de todos elevar o não matarás acima de tudo, prezar pela justiça, misericórdia e caridade, tornando esta ética inabalável, como fundamento de uma sociedade justa que condena qualquer tipo de violência, seja física e/ou simbólica.

\title{
ALGUMAS CONSIDERAÇÕES FINAIS
}

Após toda discussão aqui tecida, chega-se às seguintes conclusões: é nosso dever enquanto cientistas lutar contra esta totalidade opressora que espalha e dissemina em nossa sociedade o terror, o ódio e a violência contra o outro que é diferente de nós. Abracemos o outro como infinito, dado a ideia de não objetificar esse outro, uma vez que existe várias naturezas (DELEUZE \& GUATARRI, 2012): para quê, então, tipificar e classificar o outro? Levemos a ideia de responsabilidade para além da teorização, abrigando o outro, estimulando a caridade, a paz e o reconhecimento da união. Logo, devemos produzir novos saberes e novas formas de pensar o sujeito, como também sua existência, a fim de garantir a igualdade e liberdade, tendo em vista que o pensamento 
ocidental insiste em categorizar os indivíduos baseados numa metafísica dos sexos, que desemboca em intolerâncias, preconceitos e em discursos cujo objetivo é marginalizar o diferente. Mais do criar sistemas filosóficos abstratos, devemos também sempre nos posicionar, tendo por obrigatoriedade assumir a posição de proteger e cuidar do outro (MEDONÇA \& CARDOSO, 2018) .

Para mais, as reflexões teóricas de Levinas (2010) nos conduz a abordar a questão da liberdade de um outro jeito. Trata-se de colocar a responsabilidade antes mesmo de qualquer liberdade, pois assim o rosto que se apresentará diante de um outro exigirá uma outra forma de liberdade, não mais firmada na face egoísta, sempre voltada para si, mas numa centrada no outro, na caridade e na piedade. Consequentemente, nossa luta será constante contra a violência, discriminação e qualquer atrocidade que impedirá o outro de viver e ser feliz. Será através desse novo humanismo que almejaremos a esperança e a paz, evitando guerras e torturas, mas, antes de tudo, será a partir dessa nova ética que mostraremos as possibilidades para a humanidade trilhar um outro caminho, dando um outro sentido ao ser e ao saber, da responsabilidade, do amor e cuidado.

Por isso, tal humanismo nos levará ao reconhecimento da paz e do não matarás, privilegiando a vida. Assim, finalmente, coincidiremos com o Artigo $5^{\circ}$ da Constituição Federal, promulgada em 1988, ao qual afirma que todos são iguais perante a lei sem distinção de qualquer natureza. Posto isto, toda a discussão deste trabalho se firmou na reflexão diante dos dados das mortes de LGBT's, tendo em vista o medo do diferente e do qual estes podem acarretar em nossa sociedade. O medo do diferente, como foi visto, faz com que grande parte da população se prive em seu mundo, aceitando apenas o que lhe seja conveniente e aceitável, negando e classificando o outro como "divergente", criando assim a indiferença, a injustiça e o medo.

\section{REFERÊNCIAS BIBLIOGRÁFICAS}

BERGSON, Henri. O pensamento e o movente: ensaios e conferências. Martins Fontes, São Paulo, $1^{\text {a }}$ edição, 2006.

BRASIL. Constituição Federal Brasileira. Art. $5^{\circ}$ dos direitos e garantias fundamentais, 1988.

BUTLER, Judith. Problemas de Gênero: feminismo e subversão da identidade. Rio de Janeiro: civilização Brasileira, 15ª ed, 2017. 
DELEUZE, Gilles \& GUATTARRI, Félix. Mil platôs: capitalismo e esquizofrenia 2, Vol.4. São Paulo: Editora 34, 2012.

FOUCAULT, Michel. Vigiar e punir: nascimento da prisão. Petrópolis, RJ: vozes, $42^{\mathrm{a}}$ ed, 2014.

GIL, Antonio Carlos. Métodos e técnicas de pesquisa social. São Paulo: Editora Atlas AS, $6^{a}$ ed., 2008.

LEVINAS, Emmanuel. Entre nós: ensaios sobre a alteridade. (Trad. Pergentino Pivatto). Petrópolis, RJ: Vozes, 2010.

LOURO, Guacira. O corpo educado: pedagogias da sexualidade. Belo Horizonte: Autêntica, $3^{\mathrm{a}}$ ed, 2016.

MENDONÇA, Roberta Rayza S. \& CARDOSO, Fernando da Silva. A noção de sujeito e de diversidade humana na ontologia contemporânea dos Direitos Humanos: Diálogos entre Emmanuel Levinas e Judith Butler. Revista Científica da FASETE, p. 11-29, 2018.

MISKOLCI, Richard. Teoria queer: um aprendizado pelas diferenças. Belo Horizonte: autêntica editora: UFOP Universidade Federal de Ouro Preto, 2017.

PRECIADO, Paul B. (Beatriz). Texto junkie: sexo, drogas e biopolítica na era farmocopornográfica. Editora: n-1_edições, 2018.

SAYÃO, Sandro. Direitos Humanos e Bondade: um ensaio sobre a possibilidade da paz a partir de Emmanuel Levinas. In Cultura de paz: processo em construção (org. Suzana Damiani, Cláudia Maria Hansel, Maria Suelena Pereira de Quadros) Caxias do Sul, RS: Educs, 2017.

- Entre o Dizer e o Dito: sobre a precariedade e a finitude de nosso saber em Emmanel Levinas. Conjectura, Caxias do Sul, v. 16, n. 1, jan./abr. 2011a.

Levinas e o argumento do infinito: um diálogo com Descartes. Princípios Natal, v.18, n.30, jul./dez. 2011b, p. 143-162.

SIBILIA, P. O homem pós-orgânico: a alquimia dos corpos e das almas à luz das tecnologias digitais. 2nd ed. Rio de Janeiro: Contraponto, 2015.

TREVISAN, João Silvério. Devassos no paraíso: a homossexualidade no Brasil, da colônia à atualidade. Rio de Janeiro: Objetiva 4ª Ed, ver., atual e amp., 2018.

VIDARTE, Paco. Ética bixa: proclamações libertárias para uma militância LGBTQ. São Paulo: n-1 edições, 2019. 
Revista eletrônica de

Filosofia

Alamedas

WEISS, Raquel. A teoria Moral de Émile Durkheim. XIII Congresso da Sociedade Brasileira de Sociologia. UFPE, 2007. 